\title{
WHITMAN AS GHOSTWRITER: The Case of Rambles Among Words
}

\author{
James Perrin Warren
}

Although whitman once told Horace Traubel that Leaves of Grass was "only a language experiment," the poet's studies and theories of language have received little attention from literary scholars. ${ }^{1}$ Nor is this surprising, since Whitman published only two essays on language during his lifetime. The first, "America's Mightiest Inheritance," appeared in the 12 April 1856 issue of Life Illustrated, a "family magazine" owned by Fowler and Wells. ${ }^{2}$ The second, "Slang in America," did not appear until November 1885, in the North American Review. ${ }^{3}$ The only other linguistic work by Whitman to reach the general reading public was An American Primer, a series of notes edited by Traubel and published in $1904 .{ }^{4}$ Recently, however, several unpublished manuscripts have come to light, the most important of which is the notebook Words. ${ }^{5}$ And the work containing the most fully articulated expression of Whitman's theory of language does not even bear his name: Rambles Among Words, a popular book on English etymology, signed by William Swinton and first printed in 1859.6 In order to reconstruct Whitman's theory of language and establish its relationship to his poetic practice, therefore, it will be helpful to show that Whitman had a hand in the writing of Rambles Among Words.

In 1959, C. Carroll Hollis amassed enough cumulative evidence to conjecture that Whitman met William Swinton around November 1855, was tutored by Swinton in French and historical linguistics, and collaborated with him on Rambles Among Words. ${ }^{7}$ Basing his argument on style, Hollis identified many sections of Rambles written by Whitman, including the entire eleventh and twelfth chapters - "The Growth of Words" and "English in America," respectively. ${ }^{8}$ After examining several of the passages and comparing the vocabulary with the Whitman Concordance, however, Floyd Stovall found Whitman's unacknowledged authorship doubtful. ${ }^{9}$ Additional evidence raised further questions about Whitman's role as a ghostwriter: in the Preface to the first edition of Rambles, Swinton states that "the whole book was written half-a-dozen years ago," which would date the composition of the book in 1853 or 1854, the years when Swinton, teaching college in Greensboro, North Carolina, published two philological articles in Putnam's Monthly. ${ }^{10}$ Swinton did not arrive in New York City until 1854 or 1855, so Stovall concluded that Swinton "could not have influenced the writing of any of the poems of the first edition of Leaves of Grass, nor most of the new poems in the 1856 edition." 11 
Although Stovall overstates the case against Whitman's authorship, the problem he raises is a pressing one. The overstatement can be dealt with rather simply, for several striking words that appear in Rambles are typical of Whitman. To cite only a handful: Accouchement, Accoucheur, Electric, Ensemble, Indications, Influx, Literat, Nonchalance, Personnel, Plasticity, Rapport, Sociology, and Vista. ${ }^{12}$ But even though Stovall's case is much weaker than he allows, any explication of the theory of language contained in Rambles would be pointless without more convincing proof of Whitman's authorship. There is, however, evidence to indicate that Whitman wrote several passages from Rambles, including the important eleventh and twelfth chapters.

The first type of evidence is conceptual. In only one place does the author of Rambles actually cite Christian C. J. Bunsen, but Bunsen's Outlines of the Philosophy of Universal History, which we know Whitman studied, is an unacknowledged source for much of the linguistic theory in Rambles. ${ }^{13}$ For example, the writer of the eleventh chapter, "The Growth of Words," says that "language is not a cunning conventionalism arbitrarily agreed upon; it is an internal necessity. Language is not a fiction, but a truth" (Rambles, p. 266). The passage telescopes two statements from Bunsen's Outlines. In the first, Bunsen argues for the primordial unity between things and thoughts, sounds and meaning:

Language is the product of inward necesssity, not of an arbitrary or conventional arrangement; consequently every sound must originally have been significative of something; it must have been connected both with the sound and with the object to be expressed. (Outlines, 2:81)

The verbal parallel is clear, and no less so is the parallel between the sentence, "Language is not a fiction, but a truth," and Bunsen's statement a few pages later in Outlines, concerning "the first of all questions: why must every word be originally a true and adequate expression of the mind? Simply because language is not an arbitrary fiction, but a truth"(Outlines, 2:89).

It could of course be argued that the passages taken from Bunsen were written by William Swinton. After all, Swinton was a student of philology, and he surely must have known Bunsen's work. But it is also true that Whitman made extensive notes on Bunsen's Outlines, and a comparison of passages from "The Growth of Words," Bunsen's Outlines, and Whitman's notebook Words raises the possibility of Whitman's authorship.

In the first paragraph of "The Growth of Words," the writer makes the following statement:

The conception of language that has arisen prophetic on the thought of modern times is a high and great one. Speech is no more the dead mechanism it used to be conceived. Each language is a living organism; the totality of languages a grand series of organisms, all built after the same archetype, the same skeleton; but each presenting its special structural stamp, as fish, reptile, bird, mammal, are all modifications of one primitive Idea. (Rambles, p. 265) 
The concept behind this passage is that languages develop in the same way organisms do-always moving on an evolutionary scale and always in accordance with the unifying "one primitive Idea." Although a snake and a bird are distinctly different individuals, they are in fact modifications of the one Idea. The evolutionary process of unity within variety which we see in the world of nature is analogous, says the author of "The Growth of Words," to the process in languages.

In Words Whitman picks up the notion of unity within variety:

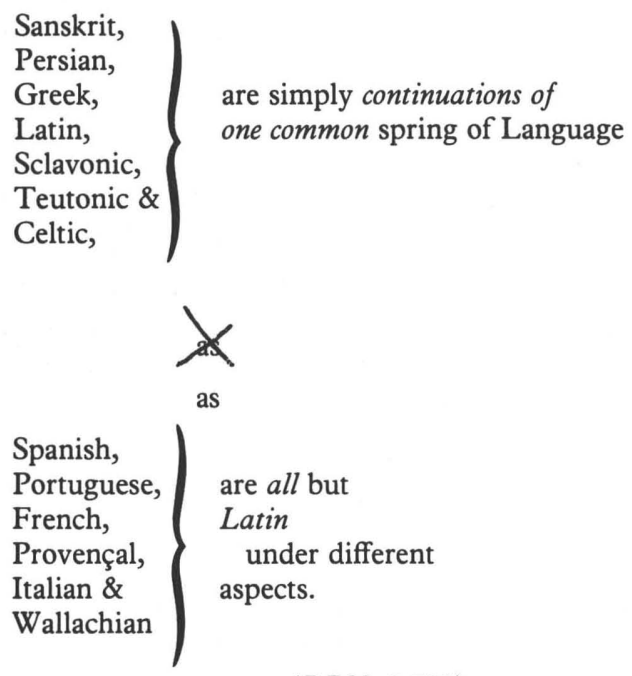

$(D B N, 3: 722)$

Whitman does not cite the page number from Bunsen's Outlines, but his note is a schematic rendering of a sentence from the conclusion ("The Possibility of a Common Origin of Language") to the first volume: "Sanskrit, Persian, Greek, Latin, Sclavonic, Teutonic, and Celtic, are simply continuations of one common spring of language, as much as Spanish and Portuguese, French and Provençal, Italian and Wallachian, are all but Latin under different aspects" (Outlines, 1:475).

In the sentence immediately preceding the one Whitman copied, Bunsen says that "on all these languages, from Sanskrit to English, there is one common stamp-a stamp of definite individuality-inexplicable if viewed as a product of nature, and intelligible only as the work of one creative genius." Bunsen's "stamp of definite individuality" becomes, in the passage from Rambles, the "special structural stamp," and his "one creative genius" becomes the more secularized "one primitive Idea." On the next page of Rambles, in an even more obvious verbal echo of Bunsen, the writer states that the "material elements and formal laws ... stamp" language "with the stamp of linguistic individuality" (Rambles, p. 266). 
The two parallels are, of course, by no means conclusive proof of Whitman's authorship. They merely suggest conceptual connections among the three texts by Swinton, Bunsen, and Whitman. In order to give strict textual proof, it is necessary to introduce two more texts by Whitman, "America's Mightiest Inheritance" and the 1856 "Letter" to Emerson which served as the preface to the second edition of Leaves of Grass. With the introduction of these two texts, Whitman's role as a ghostwriter becomes clear.

The textual evidence for Whitman's authorship is of two kinds, stylistic and organizational. In order to weigh the stylistic evidence, first consider this lengthy passage, identified by Hollis as Whitman's, from the first chapter of Rambles:

It is for America especially to evoke new realizations from the English speech. Always waiting in a language are untold possibilities. On the lips of the people, in the free unconscious utterance of the popular heart are the grand eternal leadings and suggestions.

Of all the heritages which America receives the English language is beyond all comparison the mightiest. Language of the grand stocks, language of reception, of hospitality, it is above all fitted to be the speech for America. There is nothing fortuitous in language. It is for reasons the English idiom is here. In the English, more than all others, was concentrated the spirit of the modern, breaking up the old crystalline classic mould. It is for America grandly to use this grand inheritance. No language has, no language ever had, such immense assimilation as the English. Freely it absorbs whatever is of use to it, absorbs and assimilates it to its own fluid and flexible substance. This rich copious hospitable flow is to be encouraged. (Rambles, p. 12)

The passage summarizes the argument of the twelfth chapter, "English in America," and it even displays verbal parallels with that chapter. For instance, in the second paragraph of the passage, the writer says that English contains "the spirit of the modern, breaking up the old crystal mould." The phrase is repeated in "English in America": "Into the make of the English, more than any other idiom, has converged the spirit of the modern, breaking up the crystalline structure of the classic mould" (Rambles, p. 286).

More importantly, the first sentence of the second paragraph clearly echoes the title of Whitman's published essay, "America's Mightiest Inheritance." That echo resounds all the more strongly when we compare this passage from Whitman's Primer notes:

America owes immeasurable respect and love to the past, and to ... many ancestries, for many inheritances - but of all that America $\Theta$ wes has rec'd $t \Theta$ from the past, $t \Theta$ from the mothers and fathers of laws, arts, letters, \&c. by far the greatest inheritance is the English Language-so long in growing - so fitted $(D B N, 3: 753)$

The parallels in diction and phrasing are striking. Both passages employ the word "fitted," applying it to the English language in America. Both use the same phrasing to exalt language as America's grandest inheritance: "Of all" the gifts America "receives" or "has rec'd," the English language is the "mightiest" or "greatest." 
A second parallel in phrasing, though slightly less remarkable, adds to the weight of textual evidence. In the first paragraph of the Rambles passage, the writer asserts, "Always waiting in a language are untold possibilities." In the 1856 "Letter" to Emerson, Whitman employs much the same phrasing:

A profound person can easily know more of the people than they know of themselves. Always waiting untold in the souls of the armies of common people, is stuff better than anything that can possibly appear in the leadership of the same. ${ }^{14}$

The parallel phrase, "Always waiting [. . .] untold," is persuasive in itself. And when we consider that both passages connect the "untold possibilities" of language or politics with the "common people" or "popular heart," the persuasion becomes a nearly settled conviction.

Another stylistic connection among Rambles Among Words, "America's Mightiest Inheritance," and the 1856 "Letter" renders the conviction a certainty. In "The Growth of Words" the writer makes the following prophetic assertion:

Of this superb Speech - the grandest in the world - we have no adequate treatment. There is no History of the English Language. Nor any Dictionary of the English Language. We have no such work on the English Language as the Germans possess in the "Teutonic Grammar" of Jacob Grimm, who has with masterly method and largest appreciation of modern Philology, traced the formative influences of the German speech, as it has shaped itself into conscious individuality. A History of the English Language, rising out of a full appreciation of the Philosophy of Speech (to which must go that large hospitality and impartiality that flows from the thought of the Ensemble) answering to the requirements of modern research, and after the broad, free methods America lets down, has yet to come. To the achievement of this epic work may well go the loftiest energies of both branches of the Anglican stock and speech! (Rambles, pp. 267-268)

The paragraph is a clear echo of this passage from "America's Mightiest Inheritance":

A Perfect English Dictionary has yet to be Written. - Largeness of mind is more indispensable in lexicography than in any other science. To make a noble dictionary of the English speech is a work yet to be performed. Dr. Johnson did well; Sheridan, Walker, Perry, Ash, Bailey, Kenrick, Smart, and the rest, all assisted; Webster and Worcester have done well; and yet the dictionary, rising stately and complete, out of a full appreciation of the philosophy of language, and the unspeakable grandeur of the English dialect, has still to be made-and to be made by some coming American worthy the sublime work. The English language seems curiously to have flowed through the ages, especially toward America, for present use, and for centuries and centuries of future use; it is so composed of all the varieties that preceded it, and so absorbs what is needed by it. ${ }^{15}$

A strict verbal parallel is immediately obvious. Whitman's call for "the dictionary, rising ... . out of a full appreciation of the philosophy of language," becomes, in Rambles, a call for a "History of the English Language, rising out 
of a full appreciation of the Philosophy of Speech." In addition, there is a parallel between the "largeness of mind" Whitman finds indispensable in "America's Mightiest Inheritance" and the "largest appreciation of modern Philology" the author of "The Growth of Words" praises in Jacob Grimm. Finally, the image of the English language as a flowing, absorbing, selfcomposing organism directly recalls the language employed in the first chapter of Rambles: "Freely it absorbs whatever is of use to it, absorbs and assimilates it to its own fluid and flexible substance. This rich copious hospitable flow is to be encouraged" (p. 12).

It could be argued that, despite the verbal connections, there is a conceptual gap between Whitman's interest in a "stately and complete" dictionary and the emphasis, in the passage from "The Growth of Words," upon a "History of the English Language." But that apparent gap disappears when we realize how closely Whitman linked the two projects. Take, for example, these lines from the 1856 "Letter":

Those things most listened for, certainly those are the things least said. There is not a single History of the World. There is not one of America, or of the organic compacts of These States, or of Washington, or of Jefferson, nor of Language, nor any Dictionary of the English Language. ${ }^{16}$

It is safe to conclude that Whitman collaborated with William Swinton on Rambles Among Words, for the conceptual and stylistic evidence is undeniable. But a question remains concerning the nature of Whitman's role in Rambles Among Words. Did he merely help Swinton draft parts of the book, adding stylistic touches to Swinton's prose, or was his role more fundamental? By comparing the organization of "America's Mightiest Inheritance," Swinton's first philological article in Putnam's Monthly, and "The Growth of Words," we can see that Whitman's hand in Rambles is just as guiding as guided.

Without entering into the details of Whitman's argument, we can discern from the section headings that "America's Mightiest Inheritance" follows a chronological structure. After an introduction to the noble heritage of "The English Language," Whitman considers the past, present, and future of his subject. The historical retrospect covers three sections: "Language cannot be Traced to First Origins," "Stocks and Grafts of English Speech," and "Asiatic Stock-Movements of Races." Here we see Whitman returning as nearly as possible to the inconceivable origins of English. In the next two sections, "Contributions and Parts" and "Only Language Endures," he considers the present state of American English in the light of its past development. Then he offers three sections dealing with the future prospects for American English: "Diffuse and Showy Use of Language," "A Perfect English Dictionary has yet to be Written," and "Meanness of the Tuition of Schools." Finally, he adds an "Appendant for Working-People, Young Men 
and Women, and for Boys and Girls," in which he gives a list of "Foreign Words, mostly French, put down Suggestively." Thus Whitman's chronological argument takes account of the history of the language in order to suggest practical possibilities for the future development of English in America.

In comparison with "America's Mightiest Inheritance," Swinton's article in Putnam's Monthly appears woefully unorganized. As he states in the first sentence of the piece, his purpose is "to ramble": "We have no notion of plodding through the entire journey on the dusty highway, even though it have the advantage of being the straight and established path."17 Swinton does address many of the topics treated in "America's Mightiest Inheritance," and doubtless Whitman had read the article before writing his own. But the argument of Swinton's "Ramble First" is by no means chronological. Rather, the author leaps from etymology to etymology, following the impulse of his whimsical imagination:

And now let us jump over the Norman Conquest under William the Bastard, when so very large an accession of Normanno-Franco-Celtic words was grafted on our ancient Saxon, and take a peep in at how our language gets on in the 14th century. In these rambles we are, of course, not to be considered as being encumbered with the inconvenient and rather vulgar envelopes of space and time. ${ }^{18}$

This quotation demonstrates not only a difference in argumentation but also a difference in tone. Whereas Whitman continually takes on the role of the Jeremiah-like prophet, Swinton repeatedly strikes the chords of urbane wit and snobbery. We could not ask for two more different approaches to a similar subject.

Turning to Rambles Among Words, we find this same disparateness of argumentation and tone. ${ }^{19}$ But the structure of "The Growth of Words" displays a remarkable similarity to that of "America's Mightiest Inheritance." After a two-paragraph introduction to the idea of language as a living organism (pp. 265-266), the writer engages in a long historical retrospect of the English language, tracing it from its Indo-European beginnings to the AngloSaxon "stock" and the Norman French and classical "grafts" (pp. 267-278). $\mathrm{He}$ then considers the language in its present form, mentioning the contributions of various modern languages to the English lexicon (pp. 278-280). Next, he focuses on the future prospects for English, including the role of slang and neologisms in enriching the vocabulary (pp. 280-282). Finally, he ends with a list of French words that are currently "getting into popular use" (pp. 282-285). Thus "The Growth of Words" follows exactly the same chronological order as "America's Mightiest Inheritance," moving from a theoretical consideration of the history of the language to a practical encouragement of future linguistic developments.

This is not to say that "The Growth of Words" is entirely Whitman's work, for this is demonstrably not the case. Swinton's article in Putnam's 
Monthly quotes, for instance, eight passages from Chaucer, and all eight are reproduced in "The Growth of Words." 20 But whereas in the article Swinton uses each of the eight passages separately for lengthy discussions of particular etymologies, the author of "The Growth of Words" groups the eight passages to illustrate how "it cannot be that Chaucer did anything more than crystallize into literature verbal forms already in solution among the floating word-capital of the day. For never otherwise could he have been the popular poet he was" (Rambles, p. 274). The difference between the collaborators is clear: while Swinton enjoys displaying his knowledge of etymologies, Whitman is concerned with encouraging the perpetual "growth" of the "floating word-capital" of American English. Whitman's prophetic, didactic concern thus gives both form and purpose to Swinton's technical knowledge.

Questions concerning the time, place, means, and motives of Whitman's ghostwriting Rambles Among Words must, in all likelihood, remain unanswered. But the question of Whitman's hand in the book must be answered in the affirmative. From the conceptual, stylistic, and organizational evidence, we can safely conclude that Whitman brought as much to William Swinton as Swinton did to Whitman. Stovall's question concerning Swinton's influence on Whitman, then, is no more important than the question of Whitman's influence on Swinton. The theory of language Whitman outlines in "America's Mightiest Inheritance" and in his linguistic notebooks is fully developed in "The Growth of Words" and "English in America." With these final two chapters of Rambles Among Words added to the canon of Whitman's linguistic writings, literary scholars can now begin to discuss both the poet's theory of language and the relationship of the theory to his poetic practice. ${ }^{21}$

\section{Washington and Lee University}

\section{NOTES}

1 The quoted phrase is from Walt Whitman, An American Primer, ed. Horace Traubel (Boston: Small, Maynard, 1904), pp. viii-ix.

The only book-length study of Whitman's poetic style is C. Carroll Hollis, Language and Style in "Leaves of Grass"(Baton Rouge: Louisiana State University Press, 1983). Two dissertations deserve special mention for their treatment of the poet's linguistic studies: John E. Bernbrock, S.J., "Walt Whitman and 'Anglo-Saxonism,'" Diss. North Carolina 1961; Michael R. Dressman, "Walt Whitman's Study of the English Language," Diss. North Carolina 1974. In "Walt Whitman's Language and Style," Diss. Yale 1982, I explicate Whitman's theory of language and show how the theory affects the style of Leaves of Grass.

2 Fowler and Wells also published the American Phrenological fournal, the Water-Cure Magazine, and the first two editions of Leaves of Grass. "America's Mightiest Inheritance" is reprinted in New York Dissected, ed. Emory Holloway and Ralph Adimari (New York: Rufus Rockwell Wilson, 1936), pp. 51-65.

3 The essay was reprinted in November Boughs (1888) and appears in Prose Works 1892, ed. Floyd Stovall (New York: New York University Press, 1964), II, 572-577. Whitman called the essay "insignificant"; see Horace Traubel, With Walt Whitman in Camden, I (Boston: Small, Maynard, 1906), 461-462. 
4 The Primer notes appear in Daybooks and Notebooks, ed. William White (New York: New York University Press, 1978), 3:728-757.

5 Daybooks and Notebooks, 3:644-727. All citations from the Primer and Words are taken from this edition and appear hereafter in the text, cited as " $D B N, 3$. ."

6 William Swinton, Rambles Among Words, Revised Edition (New York: Ivison, Blakeman, Taylor, 1872). This edition is not at all "revised." The pagination is identical to that of the 1859 edition, and printing errors are retained. All references are to this edition and appear in the text, cited as "Rambles."

7 C. Carroll Hollis, "Walt Whitman and William Swinton: A Co-operative Friendship," American Literature, 30 (1959), 425-449.

8 Hollis, "Co-operative Friendship," pp. 439-440, n. 40.

9 Floyd Stovall, The Foreground of "Leaves of Grass" (Charlottesville: University Press of Virginia, 1974), pp. 213-214.

10 The two articles appear in Putnam's Monthly, 4 (November-December, 1854), 472-481, 602-609. The material in the two articles is incorporated in various parts of Rambles Among Words.

11 Stovall, pp. 213-214.

12 All of these words appear in the eleventh and twelfth chapters of Rambles. The list is representative, not exhaustive; a thorough comparison of the vocabulary of Rambles with the Concordance would be interesting, but it is not necessary to refute Stovall's claim.

13 The notebook Words contains several notes on Bunsen's Outlines of Universal History, Applied to Language and Religion, 2 vols. (London: Longmans, 1854). See $D B N, 3: 719-723$, and Stovall, pp. 164-165. All quotations from Bunsen are to the above edition, cited as "Outlines."

14 Walt Whitman, The Complete Poems, ed. Francis Murphy (Harmondsworth: Penguin, 1975), p. 766.

15 New York Dissected, p. 59. For a discussion of Whitman's dictionary project, see Michael R. Dressman, "Walt Whitman's Plans for the Perfect Dictionary," Studies in the American Renaissance, 1979, ed. Joel Myerson (Boston: Twayne, 1979), pp. 457-474.

16 Complete Poems, p. 767.

17 "Rambles Over the Realms of Verbs and Substantives. Ramble First," Putnam's Monthly, 4 (Nov. 1854), 474.

18 "Ramble First," p. 476.

19 Hollis states the case succinctly: "The organization is clumsy. . . The contrast in tone from the light and sometimes jocular etymologies (which are like the original "Rambles" of Putnam's) to the exalted, intense, and frequently poetic affirmations (which are parallel to many notes in An American Primer) is so glaring that Swinton could have defended his sole authorship only on the basis of a split personality" ("Co-operative Friendship," p. 439).

20 For a discussion of Whitman's interest in Chaucer, see Michael R. Dressman, "Whitman, Chaucer, and French Words," Walt Whitman Review, 23 (1977), 77-82. Dressman does not treat Swinton's role in "The Growth of Words," but his discussion of other manuscript materials is helpful.

21 For an attempt at the latter project, see my "The 'Real Grammar': Deverbal Style in 'Song of Myself,'” American Literature 56 (March 1984), 1-16. 